Nalan Şanlı

Nigar Bircan Ocak

Kerem Erkalp

Mehmet Salih Sevdi

Ayşin Alagöl

\section{Intramusküler Diklofenak Sodyum Enjeksiyon Sonrası Toksik Epidermal Nekroliz ve Çoklu Organ Yetmezliği: Olgu Sunumu}

\author{
Toxic Epidermal Necrolysis and Multiple Organ \\ Failure After Intramusculer Diclofenac Sodium Injection \\ A Case Report
}

Geliș Tarihi/Received: 22.05.2013

Kabul Tarihi/Accepted: 05.09.2013

Türk Yoğun Bakım Derneği Dergisi, Galenos Yayınevi tarafindan basilmıstır.

Journal of the Turkish Society of Intensive Care, published by Galenos Publishing.

ISNN: 1300-5804

Nalan Şanlı, Nigar Bircan Ocak, Kerem Erkalp (凶), Mehmet Salih Sevdi, Ayșin Alagöl,

Bağcılar Eğitim ve Araştırma Hastanesi, Anestezi ve

Reanimasyon Kliniği, Bağcılar, Istanbul, Türkiye

E-posta: keremerkalp@hotmail.com

Tel.: +90 5327879500
ÖZET Intramusküler enjeksiyon, çok sık uygulanan temel bir tıbbi girişimdir. Illk akla gelen komplikasyonu siyatik sinir hasarı olsa da yumuşak dokuyu ilgilendiren sorunlarla da karşılaşılmaktadır. Enjeksiyonun kas içi yerine hipodermal alana yapılması, hızla gelișen nekroza yol açabilir. Ayrıca uygulanan ilaca karșı aşırı bir immün cevap da görülebilir ki bu tabloya toksik epidermal nekroliz adı verilir. Yazımızda; intramusküler nonsteroid antiinflamatuar ilaç enjeksiyonunu takiben ağır sepsisle karşıladığımız ve çoklu organ yetmezliği nedeni ile ölen bir toksik epidermal nekroliz olgusunu sunduk.

Anahtar Kelimeler: Intramusküler enjeksiyon, nonsteroid antiinflamatuar ilaç, toksik epidermal nekroliz, sepsis, çoklu organ yetmezliği

\begin{abstract}
SUMMARY Intramuscular injection is the most commonly performed a basic medical intervention. Even though the first that comes to mind, damage to the sciatic nerve complications; problems related to soft tissue encountered. Instead of muscular injection to hipodermal area, it can lead to necrosis which fastest growing. In addition, an excessive immune response to the drug can be seen; it is named that toxic epidermal necrolysis. In this article, we presented a toxic epidermal necrolysis case who died due to severe sepsis and multiple organ failure after intramuscular injection of nonsteroidal anti-inflammatory drug.
\end{abstract}

Key Words: Intramuscular injection, nonsteroidal anti-inflammatory drug, toxic ep idermal necrolysis, sepsis, multiple organ failure

\section{Giriş}

Toksik Epidermal Nekroliz (TEN), vücudun çeşitli antijenlere karşı geliştirdiği, keratinositlerin immün sitotoksik yıkımıdır (1). En sık olarak ilaçlara [antibiyotikler, allopürinol, nonsteroid antiinflamatuar ilaçlar (NSAll), antikonvülzanlar] bağlı olarak gelişse de infeksiyon, kanser ve aşı uygulanması sonrasında da görülebilir $(2,3)$.
TEN cildin \%30'undan fazlasının tutulumu ile hızla ilerleyen sistemik, ciddi bir hal alır. Agresif tedavi gerektiren yüksek mortalite ile ilişkili çoklu organ yetmezliğine neden olur. Yılda 0,4-1,3/milyon kişi insidansı ile görülen TEN \% 1030 mortaliteye sahiptir (4).

Bu olgu sunumunda intramusküler (IM) NSAll uygulaması sonrasında TEN ve çoklu organ yetmezliği gelişen ve sonrasında ölen bir hasta sunuldu. Literatür bilgileri ile beraber 
IM NSAll uygulaması, TEN ve çoklu organ yetmezliği (ÇOY) ilişkisi tartışıldı.

\section{Olgu Sunumu}

Kırk sekiz yaşında erkek hasta hastanemiz acil servisine 4 gündür sol bacakta şişme, kızarma, morarma, kabuklanma, soyulma, ani gelişen genel durum bozukluğu ve şuur kaybı ile başvurdu. Oratrakeal entübe halde ve ambu ile ventilasyonu sağlanarak reanimasyon ünitemize yatıııld. Şuuru kapalı, pupilleri ışığa cevaplı, ağrılı uyarana yanıtı belirsiz, akciğer sesleri kaba, batını rahat, tüm periferik nabızlar çok zayıf palpe edilebilir, sol bacakta morarma, şişme, soyulma, dolaşım bozukluğu mevcuttu. Vücut sıcaklığı 38,4 ${ }^{\circ} \mathrm{C}$ idi. TA: 55/33 mmHg, KTA:142 vuru/dk, \%100 $\mathrm{O}_{2}$ ile $\mathrm{SpO}_{2}: \% 88$, arteriyel kan gazında hipoksi $\left(\mathrm{PaO}_{2}: 57 \mathrm{mmHg}\right)$ ve metabolik asidoz $(\mathrm{pH}: 7,14)$ saptandı. Bir hafta öncesinde gribal enfeksiyonu olan hastaya 5 gün önce bir sağlık merkezinde sol gluteal bölgeden IM diklofenak sodyum enjeksiyonu yapıldığı, ardından enjeksiyon bölgesinden bacağına hızla yayılan şişlik ve morluk olduğu, son bir gündür de hastanın genel durumunun kötüleştiği öğrenildi. Hemogramında lökositozu $\left(19,8103 \mathrm{~mm}^{3}\right)$ biyokimyasal değerlerinde ise böbrek (üre: $156 \mathrm{mg} / \mathrm{dL}$, kreatinin: 2,3 mg/dL) ve karaciğer fonksiyon bozukluğu (ALT: $2565 \mathrm{U} / \mathrm{L}$, AST: $1425 \mathrm{U} / \mathrm{L}$, INR: 3) bulguları, hiperkalemi (K: 6,2 mEq/dL), CRP yüksekliği (184 mg/L), koagülasyon bozukluğu (protrombin zamanı: 24 sn, trombosit sayısı: $56103 \mathrm{~mm} 2$ ) mevcuttu. Agresif sıvı resüsitasyon tedavisi $(20 \mathrm{ml} / \mathrm{kg} / \mathrm{saat}$ kristalloid) uygulanan hastada 6 saatlik takip sonrasında anürinin devam etmesi üzerine, sitrat antikoagülasyonlu devamlı venovenöz renal replasman tedavisi başlandı, inotrop ilaç desteği (dopamin $15 \mu \mathrm{g} / \mathrm{kg} / \mathrm{dk}$, noradrenalin $0,3 \mu \mathrm{g} / \mathrm{kg} / \mathrm{dk}$, dobutamin $12 \mu \mathrm{g} / \mathrm{kg} / \mathrm{dk}$ ) sağlandı. Balgam, idrar, kan ve yara yeri kültürleri alındıktan sonra ampirik antibiyoterapisi (meropenem $3 \mathrm{~g} / \mathrm{gün}$, vankomisin

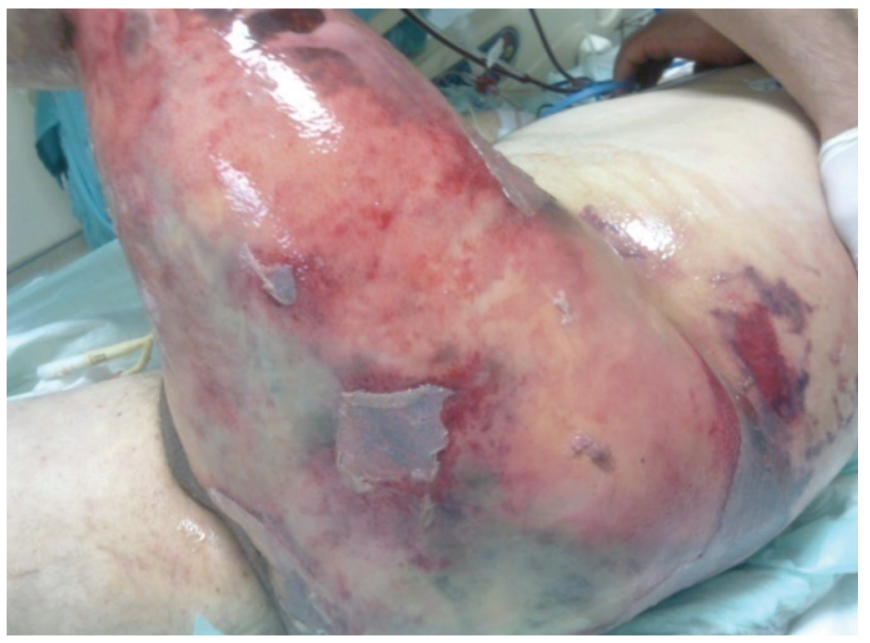

Resim 1. Hastanın sol alt ekstremite proksimali
$2 \mathrm{~g} / \mathrm{gün}$ ) sistemik kortikosteroid (metilprednizolon $1 \mathrm{mg} / \mathrm{kg}$ günde iki kere) başlanan hastanın vital fonksiyonları daha stabil olduğunda, alt ekstremiteye bilateral Doppler USG ile radyolojik inceleme yapıldı. Sol alt ekstremite kan akımının azalmış olduğu saptandı. Ortopedi, damar cerrahisi, plastik cerrahi ve dermatoloji konsültasyonları sonucunda, cilt ve ciltaltı gelişen bir toksik reaksiyon olduğu görüşüne varıldı. Amputasyon, revaskülarizasyon, fasyatomi gibi cerrahi girişim fikirlerinden uzaklaşıldl; semptomatik tedavi görüşünde birleşildi. Klinik durumunda iyileşme oluşmayan hasta, yatışının yedinci gününde ÇOY nedeni ile kaybedildi. Hastadan yatışında alınan biyopsi sonucu on beşinci günde TEN ile uyumlu idi.

\section{Tartışma}

IM enjeksiyon sonrası komplikasyon gelişme sıklığı \%0,419,3 arasında değişmektedir (5,6). Görülen komplikasyonlar arasında kanama, hematom oluşumu, damar içine enjeksiyon, sinir hasarı, ağrı, apse oluşumu, doku nekrozu, skar oluşumu, eklem kontraktürü ve psödotümör gelişimi yer alır (7). Enjekte edilen ilaç kas yerine subkutan dokuya bırakıldığında emilimi gecikir ve böylece daha fazla doku reaksiyonu görülür. Bu reaksiyon lokal doku nekrozu ile likenifikasyona ve enflamasyona neden olur (8-10). Kas içine yapılan enjeksiyonlar lokal bir patolojik etkiye neden olmaz; çünkü kasın kan dolaşımı çok zengindir. Yağ dokusu, yetersiz drenaj kanalları nedeni ile enjekte edilen maddelere daha uzun süre maruz kalarak, zararlı etkilerinden daha fazla etkilenmektedir (11).

IM enjeksiyon sonrası infeksiyonların en sık sebebi ise S. aureus'tur (12). Nadir de olsa sepsis tablosu oluşturabilen hatta olgumuzdaki gibi fatal seyreden durumlar da oluşabilmektedir (13). Bu bilgiden dolayı hastanın yatışındaki ampirik antibiyoterapi dozlarını meropenem 3 g/gün, vankomisin $2 \mathrm{~g} / \mathrm{gün}$ olacak şekilde belirledik.

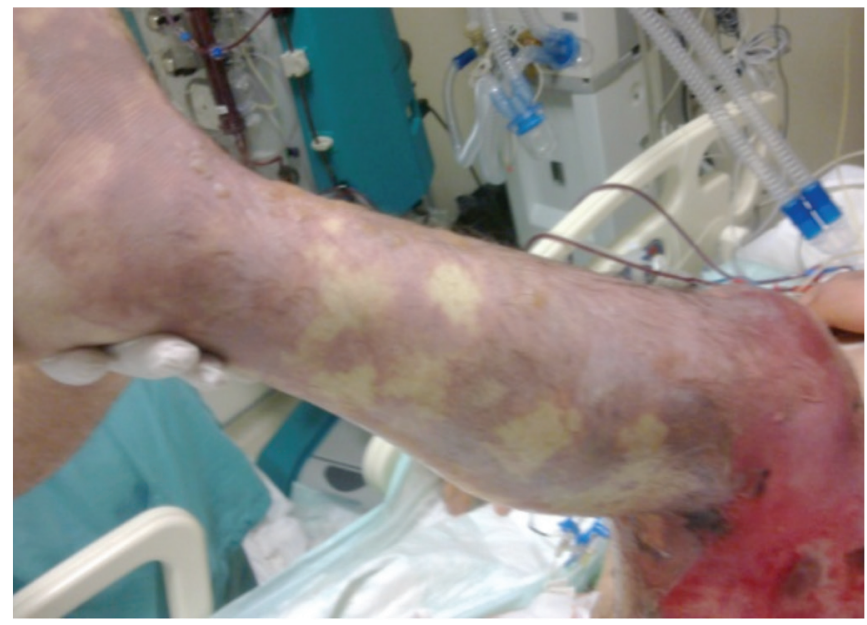

Resim 2. Hastanın sol alt ekstremite distali 
TEN, Stevens-Johnson Sendromu (SJS) ya da Eritema Eksudativum Multiforme Majus olarak da bilinen bu hipersensitivite reaksiyonu, viral veya bakteriyel infeksiyonlarla birlikte görülürken, çoğu zaman bir ilaç kullanımı ile birliktedir ki en sık suçlanan ajanlar; allopürinol, karbamazepinler, kotrimoksazol ve oksikam türü NSAll'dır (14). Kortikosteroidlerin de infeksiyöz komplikasyonlara yol açabileceği düşünülse de TEN'in akut dönemde tedavide kullanılması önerilmektedir (15). Hastamızda da IM NSAll uygulaması ve sonrasında gelişen bir infeksiyon varlığı sözkonusu idi.

TEN'de mortalite oranı \%10-30 arasında değişmekle birlikte; yaş, malignite varlığı, yaygın cilt bulgusu, taşikardi, hiperglisemi, asidoz ve üremi varlığında prognoz kötüleşir $(4,16)$. Bu tür hastalarda yoğun bakım hekimini bekleyen sorunlar; asit-baz ve elektrolit dengesizlikleri, hipovolemi, artmış katabolizma, septisemi ve çoklu organ yetmezliğidir (17). Literatürde intravenöz immünglobülin (IVIG) uygulamasının, plazmaferezin, hiperbarik oksijen tedavisinin ve siklofosfamidin de TEN tedavisinde kullanıldığını bildiren az sayıda bildiri bulunmaktadır (18-21). Graft Versus Host Hastalığı'nda kullanılan, TNF alfa inhibitörü talidomid de; TEN olgularında kullanılmış ve başarılı sonuçlar elde edilmiştir. (22). Hastamızda kortikosteroidler ile birlikte destek tedavisi uyguladık.Sonuç olarak, olgumuzda duyarlılığı arttıran faktörün IM NSAll enjeksiyonu olduğunu varsayarak; temel ve basit bir tıbbi girişim olan IM enjeksiyon uygularken; iğne boyunun yağ dokusu fazla olan kişilerde $3,8 \mathrm{~cm}$ 'den uzun seçilmesine, iğnenin vücuda dik olarak sokulmasına, kas içinde olunduğuna emin olmak için iğnenin dokuya sıkı sıkıya saplandığını hissetmeye (iğne kas dokusu içinde iken hareket etmez), aynı bölgeye tekrarlayan enjeksiyonlardan kaçınılmasına dikkat etmek gerekir (23-24).

\section{Çıkar Çatışması \\ Yazarlar herhangi bir çıkar çatıșması bildirmemișlerdir.}

\section{Kaynaklar}

1. Mayrink M, Mendonça AC, da Costa PR Soft-tissue sarcoma arising from a tissue necrosis caused by an intramuscular injection of diclofenac. Plast Reconstr Surg 2003;112:1970-1.

2. Hay J. Complications at site of injection of depot neuroleptics. BMJ 1995;311:421.

3. Treadwell T. Intramuscular injection site injuries masquerading as ulcers. Wounds 2003:15:302-12.

4. Ghislain PD, Roujeau JC. Treatment of severe drug reactions: Stevens-Johnson syndrome, toxic epidermal necrolysis and hypersensitivity syndrome. Dermatol. Online J 2002;1:5.

5. Tesio L, Bassi L, Strada L. Spinal cord lesion after penicillin gluteal injection. Paraplegia 1992;30:442-4.

6. Zelman S. Abscesses from parenteral injection. JAMA 1978;240:23.

7. Michaels L, Poole RW. Injection granuloma of the buttock. Can Med Assoc J 1970;102:626-8.

8. Kim SK, Kim TH, Lee KC. Nicolau syndrome after intramuscular injection: 3 cases. Arch Plast Surg 2012;39:249-52

9. Nischal K, Basavaraj H, Swaroop M, Agrawal D, Sathyanarayana B, Umashankar N. Nicolau syndrome: an iatrogenic cutaneous necrosis. J Cutan Aesthet Surg 2009;2:92-5.

10. Mockenhaupt M. Severe cutaneous adverse reactions. In: Braun-Falco's Dermatology (3rd Edition). Burgdorf WHC Plewig G, Wolff HH, Landthaler M (Eds). Springer Medizin Verlag, Heidelberg, Germany, 2008;473-83.
11. Frid A, Hirsch L, Gaspar R, Hicks D, Kreugel G, Liersch J, et al. New injection recommendations for patients with diabetes. Diabetes Metab 2010;36:3-18.

12. Rygnestad T, Kvam AM. Streptococcal myositis and tissue necrosis with intramuscular administration of diclofenac (Voltaren). Acta Anaesthesiol Scand 1995;39:1128-30.

13. Velissaris D, Matzaroglou C, Kalogeropoulou C, Karamouzos V, Filos K, Karanikolas M. Sepsis requiring intensive care following intramuscular injections: two case reports. Cases J 2009;2:7365

14. Kaufman DW, Kelly JP. Acetylsalicylic acid and other salicylates in relation to Stevens-Johnson syndrome and toxic epidermal necrolysis. Br J Clin Pharmacol 2001;:51:174-6.

15. Kardaun SH, Jonkman MF. Dexamethasone pulse therapy for Stevens-Johnson syndrome/toxic epidermal necrolysis. Acta Derm Venereol 2007;87:144-8.

16. Fritsch PO, Sidoroff A. Drug-induced Steven-Johnson syndrome/toxic epidermal necrolysis. Am J Clin Dermatol 2000;1:349-60.

17. Khalaf D, Toema B, Dabbour N, Jehani F. Toxic epidermal necrolysis associated with severe cytomegalovirus infection in a patient on regular hemodialysis. Mediterr J Hematol Infect Dis 2011;3:e2011004. doi: 10.4084/MJHID.2010.004.
18. Faye O, Roujeau JC. Treatment of epidermal necrolysis with high-dose intravenous immunoglobulins (IVIG): clinical experience to date. Drugs 2005;65:2085-90

19. Del Pozzo-Magana BR, Lazo-Langner A, Carleton B, Castro-Pastrana LI, Rieder MJ. A systematic review of treatment of drug-induced Stevens-Johnson syndrome and toxic epidermal necrolysis in children. J Popul Ther Clin Pharmacol 2011; 18:121-33.

20. Ruocco V, Bimonte D, Luongo C, Florio M. Hyperbaric oxygen treatment of toxic epidermal necrolysis. Cutis 1986;38:267-71.

21. Carmona AF, Redondo AD, Peña LO, Gómez AG, Pareja JC, Martínez JL. Toxic epidermal necrolysis treated with cyclosporin A]. Med Intensiva 2011;35:442-5.

22. Worswick S, Cotliar J. Stevens-Johnson syndrome and toxic epidermal necrolysis: a review of treatment options. Dermatol Ther 2011;24:207-18.

23. Mishra $P$, Stringer MD. Sciatic nerve injury from intramuscular injection: a persistent and global problem. Int J Clin Pract 2010;64:1573-9.

24. Wittich CM, Ficalora RD, Mason TG, Beckman TJ. Musculoskeletal injection. Mayo Clin Proc 2009;84:831-6. 